\title{
DETERMINATION OF NEEDED PARAMETERS FOR MEASURING TEMPERATURE FIELDS IN AIR BY THERMOGRAPHY
}

\begin{abstract}
Martin PEŠEK’, Milan PAVELEK••
Abstract: The aim of this article is the parameters determination of equipment for measuring temperature fields in air using an infrared camera. This method is based on the visualization of temperature fields in an auxiliary material, which is inserted into the non-isothermal air flow. The accuracy of air temperature measurement (or of surface temperature of supplies) by this method depends especially on (except for parameters of infrared camera) the determination of the static and the dynamic qualities of auxiliary material. The emissivity of support material is the static quality and the dynamic quality is time constant. Support materials with a high emissivity and a low time constant are suitable for the measurement. The high value of emissivity results in a higher measurement sensitivity and the radiation temperature independence. In this article the emissivity of examined kinds of auxiliary materials (papers and textiles) is determined by temperature measuring of heated samples by a calibrated thermocouple and by thermography, with the emissivity setting on the camera to 1 and with the homogeneous radiation temperature. Time constants are determined by a step change of air temperature in the surrounding of auxiliary material. The time constant depends mainly on heat transfer by the convection from the air into the auxiliary material. That is why the effect of air temperature is examined in this article (or a temperature difference towards the environmental temperature) and the flow velocity on the time constant with various types of auxiliary materials. The obtained results allow to define the conditions for using the method of measurement of temperature fields in air during various heating and air conditioning applications.
\end{abstract}

\section{INTRODUCTION}

Infrared camera is a very effective device for a noncontact measurement of temperature fields in many scientific disciplines. This measuring method provides a visual image records, allowing qualitative and quantitative information for a deeper knowledge of thermal conditions and the thermodynamic processes in the research object. The thermography is being used mainly for determining surface temperatures,

\footnotetext{
- Ing., Energy Institute, Faculty of Mechanical Engineering, Brno UT, Technická 2896/2, Brno, tel. (+420) 541143 241, e-mail ypesek02@stud.fme.vutbr.cz

- Prof. Ing. CSc., Energy Institute, Faculty of Mechanical Engineering, Brno UT, Technická 2896/2, Brno, tel. (+420) 541143 272, e-mail pavelek@fme.vutbr.cz
}

This is an Open Access article distributed under the terms of the Creative Commons Attribution License 2.0, which permits unrestricted use, distribution, and reproduction in any medium, provided the original work is properly cited. 
but this article tries to extend the possibilities of monitoring and measurement of temperature fields in the air.

Immediate knowledge of the distribution of temperature field in the nonisothermal airflow can allow to quickly identifying a possible problem such as the design of air conditioning or hot-air heating. The visualization of temperature fields in the air can also detect the spatial and time context of monitored processes.

Concerning the fact that the air is transmissive, it is necessary to determine the temperature in the nonisothermal airstream by using suitable auxiliary material for visibility of temperature fields. The important factor is to define the most suitable materials that can be used for monitoring the temperature distribution in the air using thermovision camera by the method of inserting sheets of paper or other auxiliary material into nonisothermal airstream. This material must have suitable static properties, mainly high emissivity. Also, to practical application of that method of measuring temperature fields to knowledge of the dynamic properties, especially the knowledge of the time constant as function of air temperature difference and the air velocity required.

\section{EMISSIVITY}

The emissivity is one of the basic static properties of auxiliary material at measurements of temperature fields in the air by thermography. Materials for thermovision measurements of air temperatures should have especially high emissivity $\varepsilon[-]$ in order to maximize the accuracy and for noninfluence of high ambient radiation temperature $T_{R}[\mathrm{~K}]$. Emissivity has also an influence on the determination of time constant of this measurement method. By searching of suitable material different types of papers and fabrics were compared. An emissivity measurement of the studied materials was performed in the laboratory with a homogeneous radiation temperature. The radiation ambient temperature was determined by the radiation thermometer Testo 830-T2, as the arithmetic average of radiation temperature of surrounding surfaces (walls, ceiling and floor).

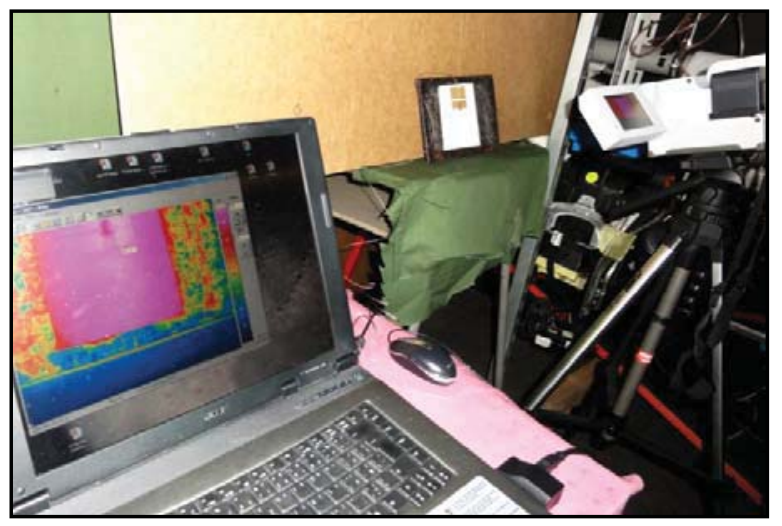

Figure 1: Emissivity measurement of support material

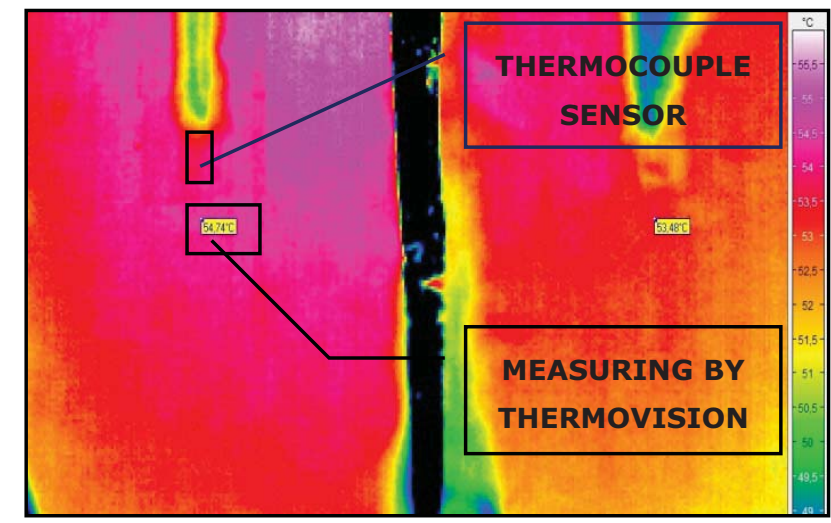

Figure 2: Thermogram of the emissivity measurements 
The emissivity of the studied materials was measured on samples heated in the cooler environment by the sample temperature from $40^{\circ} \mathrm{C}$ to $80^{\circ} \mathrm{C}$. In case the samples were heated at higher temperature, it could lead to degradation of material properties and the high air temperature warm air heating system don't correspond with the quality of indoor environment [1]. In the other case when the samples were heated lower than $40^{\circ} \mathrm{C}$, sufficient temperature difference between surrounding environment, radiation temperature and the material 's temperature shouldn' $t$ be given.

Such case would lead to an increase of measurement uncertainties. This temperature difference should be at least $25 \mathrm{~K}$ warmer in the measurement of samples in a cooler environment and in the opposite option at least $15 \mathrm{~K} \mathrm{[2].}$

Measurements were performed by the thermovision camera Jenoptik, type VarioCam that has the spectral sensitivity from 8 to $13 \mu \mathrm{m}$ with the resolution of $320 \times 240$ pixels and with the scanning frequency of 50 frames per second. The studied material was fixed to a thick steel plate with an adhesive that didn't change properties of the material on the surface. On the plate calibrated thermocouple was placed, which measured the actual temperature. Then the plate was heated up to approximately $85{ }^{\circ} \mathrm{C}$ and it was placed in the rack before the thermovision camera with set up at the right angle to the direction of observation by the thermovision camera (Figure 1).

For evaluation the emissivity of material, the temperature $T_{C}[\mathrm{~K}]$ was determined from thermogram (with setting thermovision camera of emissivity to value 1 ), the sample surface temperature $T_{T}[\mathrm{~K}]$ was measured by thermocouples and the radiation ambient temperature $T_{R}[\mathrm{~K}]$ was determined by the radiation thermometer. As a reference temperature readings were taken from the thermocouple $T_{T}[\mathrm{~K}]$. Temperature readings were held at intervals of $5 \mathrm{~K}$ from the temperature of $80^{\circ} \mathrm{C}$ to $40^{\circ} \mathrm{C}$. The final emissivity of material is given by the relationship [2]

$$
\varepsilon=\frac{T_{C}^{n}-T_{R}^{n}}{T_{T}^{n}-T_{R}^{n}} .
$$

where $n[-]$ is the exponent in the selected, suitable for the wavelength range of thermovision camera VarioCam and for temperature range investigated.

\begin{tabular}{|c|c|c|c|}
\hline \multicolumn{2}{|r|}{ The type of auxiliary material } & Weight $\left[\mathrm{g} / \mathrm{m}^{2}\right]$ & $\varepsilon[-]$ \\
\hline \multirow{3}{*}{$\begin{array}{l}n \\
\frac{n}{2} \\
\frac{0}{0} \\
0 \\
0\end{array}$} & Plain office paper & 80 & 0,96 \\
\hline & Cardboard drawing & 180 & 0,93 \\
\hline & Tracing paper & 75 & 0,91 \\
\hline \multirow{4}{*}{ 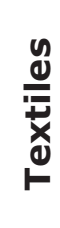 } & Cotton textile & 145 & 0,93 \\
\hline & Elastic material $70 \%$ Cotton, $30 \%$ Lycra & 130 & 0,90 \\
\hline & Denim & 270 & 0,81 \\
\hline & Table linen - $100 \%$ polyester & 195 & 0,67 \\
\hline
\end{tabular}

Figure 3: Emissivity values of auxiliary material

For each measurement the radiation temperature of surrounding environment was read by the radiation thermometer and the mean value was determined. The final 
mean emissivity of the material was calculated according to (1) in the temperature range from $80^{\circ} \mathrm{C}$ to $40^{\circ} \mathrm{C}$ and determined as the arithmetic average of the measured emissivity at $5 \mathrm{~K}$ intervals. Monitored samples of materials are given in the table (Figure 3), where there are auxiliary materials with higher emissivity values. To determine the time constant $T_{0}[\mathrm{~s}]$ by this method, a plain office paper and cotton textile was chosen.

\section{TIME CONSTANT}

Sheet of the auxiliary material (cotton textile and paper with the highest emissivity) was fixed to the sliding stand above the heat source (different types of hot-air fans) and the thermovision sequence was scanned with different temperatures and fan speeds with a step change position of the auxiliary sheet. Infrared thermovision sequences were scanned by the camera Jenoptik type VarioCam. Photos from the measurements are shown in the figure (Figure 4).

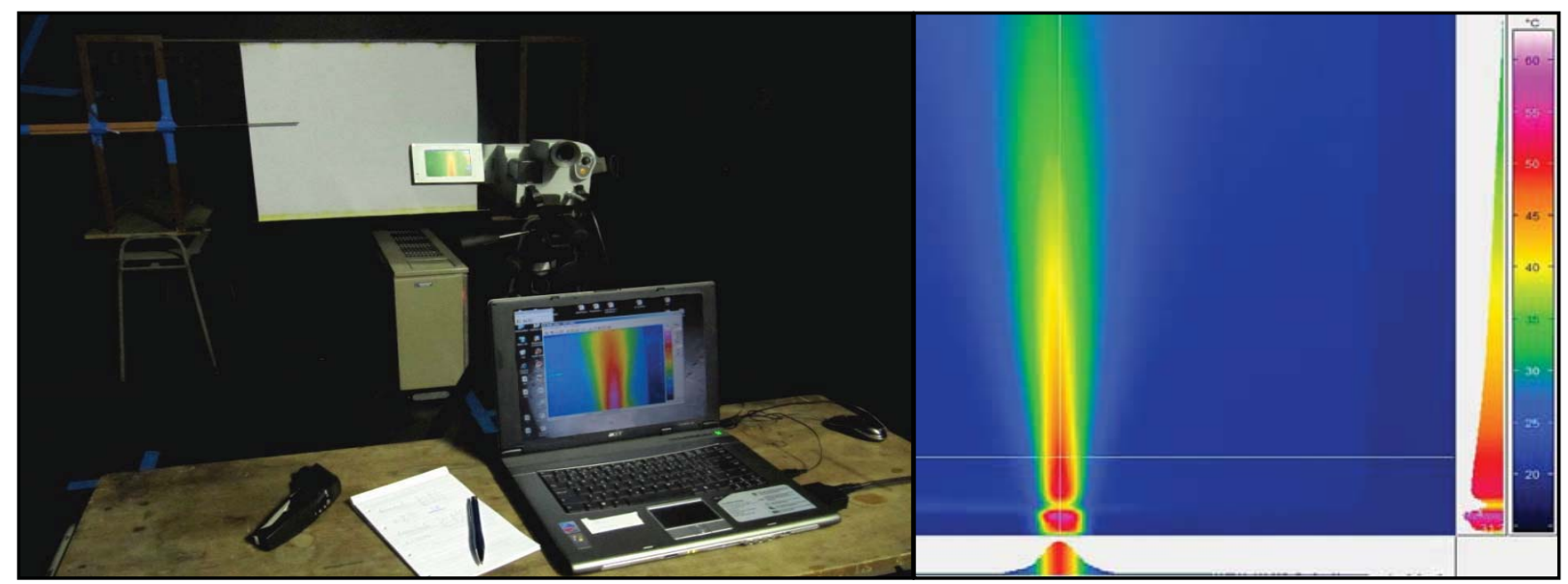

Figure 4: Photography and thermogram the time constant determination

On the base of theoretical analysis and the measured values it can be assumed that this is a system with one time constant $T_{0}[\mathrm{~s}]$. This constant can be determined from this equation:

$$
\tau_{0}=\tau(0,632 \cdot \Delta T) \quad \Delta T=T_{i=}-T_{S .}
$$

where $T_{. .}\left[{ }^{\circ} \mathrm{C}\right]$ is the steady value of surface temperature of the auxiliary material and $T_{s}\left[{ }^{\circ} \mathrm{C}\right]$ is the surrounding temperature. This time constant is a function of air velocity and the temperature difference of nonisothermal air flow due to the surrounding temperature. It was also necessary to measure the velocity and the temperature fields with resistance-type anemometer Testo 491 and thermocouples in order to compare the time constant for different velocities and temperature differences. Infrared sequences were evaluated in the program IRBIS Professional 2.2. Imaging of step changes were performed with a frequency of 50 frames per second for 10 minutes (to the surface temperature was stabilized). Time constants in each of measurement points were subsequently determined by the equation (2). In the figure the dependence of time constant this method is given on airflow speeds and temperature differences for the cotton textile. 
The time constant $T_{0}[\mathrm{~s}]$, which is lowest with highest temperature difference $\Delta T[\mathrm{~K}]$ and with highest velocity $w[\mathrm{~m} / \mathrm{s}]$ is shown in figure (Figure 5 ).

\section{Conclusion}

Among the examined materials the best properties have plain office paper for exploring the temperature distribution in the nonisothermal airstream. It has the highest emissivity. Other types of papers have lower emissivity values and the measurement is difficult due to their mechanical properties. The fabric can be well stored and mobile, but its properties for measuring of temperature fields by the infrared camera in air are less suitable for the lower emissivity compared to office paper.

Calculated values of the time constants are important for creating a methodology for measuring of temperature fields in the air by the infrared camera. Time constants together with auxiliary material emissivity and particular parameters of infrared camera in order to define the boundaries application of this method by low velocities and small temperature differences.

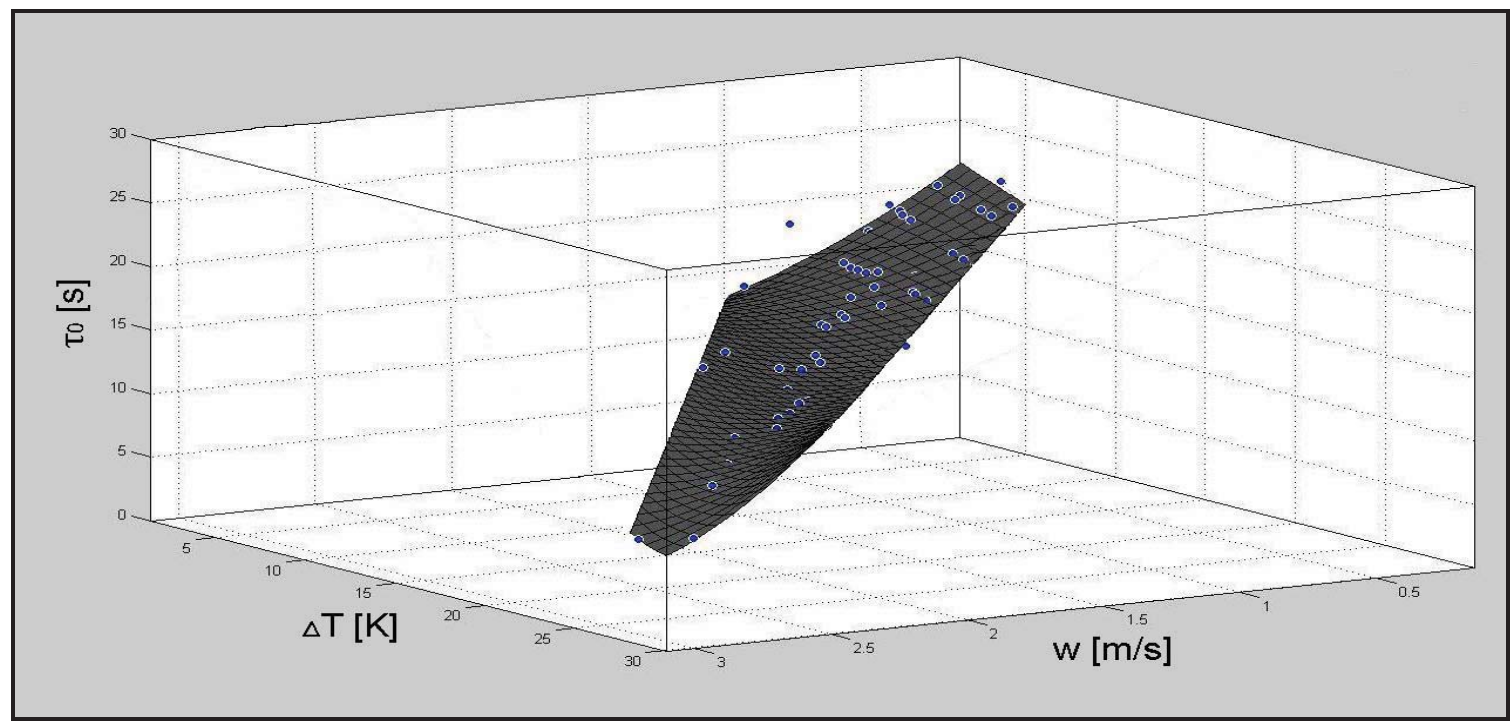

Figure 5: Dependence of time constants, airflow speeds and temperature differences for the cotton textile $145 \mathrm{~g} / \mathrm{m}^{2}$

\section{ACKNOWLEDGEMENT}

The support of this research from Czech Science Foundation project no. GA 101/09/H050 "Research into energy-saving devices to achieve comfort of the internal environment" and the standard project FSI-S-11-6 "Human Centered Design" is gratefully acknowledged.

\section{REFERENCES}

[1] ČSN EN ISO 7730.: Mírné tepelné prostředí. Stanovení ukazatelů PMV a PPD a popis podmínek tepelné pohody. Praha. Český normalizační institut, 1997.

[2] Pavelek, M.; Janotková, E.: Rozbor parametrů ovlivňujících změny povrchových teplot stavebních konstrukcí budov. Strojárstvo/Strojírenství. 2009, No. mimoriadne, s. 197-200, ISSN 1335-2938 